\title{
Programa Nacional do Livro Didático PNLD Campo: até que enfim! ${ }^{1}$
}

\author{
Simone Sarmento ${ }^{2}$ \\ Juliana Batistti ${ }^{3}$
}

\section{Resumo}

Este artigo tem como objetivo acercar-se do Programa Nacional do Livro Didático Campo (PNLD Campo), com vista a observar as especificidades do mesmo. Para isso, o trabalho traz destaques importantes em relação a essa política pública, documentos oficiais que explicam e decretam ações das políticas educacionais para o campo, bem como especificações sobre questões relacionadas à língua portuguesa, de forma a desvelar diretrizes da política linguística subjacente aos documentos. Além disso, questionários com os professores que lecionam em áreas rurais foram feitos com o objetivo de se conhecer o processo de seleção das obras didáticas aprovadas, assim como a adequabilidade da coleção escolhida ao contexto para o qual foi criado.

Palavras-chave: Livro didático. Programa Nacional do Livro Didático Campo. Seleção do livro didático.

1 O presente artigo é assim nomeado porque se refere a títulos de notícias encontrados em sites e blogues na época em que a notícia sobre a implementação do PNLD campo foi publicada.

2 Professora Adjunta do Programa do Programa de Pós-graduação em Letras da Universidade Federal do Rio Grande do Sul.

3 Mestranda em Linguística Aplicada - Programa de Pós-graduação em Letras da Universidade Federal do Rio Grande do Sul. 


\title{
National textbook program for rural areas: at last!
}

\begin{abstract}
This paper aims at drawing on the specifications of the National Textbook Program for rural areas (PNLD for rural areas). This way, it brings important highlights regarding the public policy, i.e., official documents that explain and enact actions of educational policies for the rural areas, as well as particularities on issues related to the Portuguese language area, in order to unveil guidelines of the language policy underlying the documents. In addition, questionnaires to teachers who work in rural areas were carried out so as to disclose the process of choosing the textbooks, as well as the suitability of the selected collection to the context for which it was created.
\end{abstract}

Keywords: Textbook. National Textbook Program for rural areas. Textbook selection.

\section{Introdução}

Segundo o Fundo Nacional de Desenvolvimento da Educação (FNDE) (BRASIL, 2012), autarquia federal que gerencia o PNLD, o programa surgiu no ano de 1929, com a criação do Instituto Nacional do Livro, para legalizar o Livro Didático (doravante LD) e incentivar a sua produção. A primeira política de legislação, controle e produção de livros didáticos foi instaurada por meio da criação da Comissão Nacional do Livro Didático (CNLD - Decreto-lei ${ }^{\circ}{ }^{1006)}$. Desde então, o Programa como um todo já sofreu diversas modificações em relação aos mais variados pontos que o constitui, já tendo passado por outras denominações e formatos. O principal objetivo do PNLD é "prover as escolas públicas de ensino fundamental e médio com livros didáticos e acervos de obras literárias, obras complementares e dicionários" (BRASIL, 2012)4. O programa busca

4 Texto disponível em: http://www.fnde.gov.br/programas/livro-didatico/livro-didatico-apresentacao 
atender a todas as escolas da rede pública, estadual, municipal e federal, caracterizando-se como um dos maiores projetos que oferece acesso a livros em âmbito global.

A partir da Resolução no 40, de 26 de julho de 2011, foi incluído no programa atendimento diferenciado para as comunidades rurais de todo o país. Fundamentado na Política de Educação do Campo, o nomeado PNDL Campo teve sua primeira edição em 2013, e terá a segunda em 2016, com vistas a atender as escolas pertencentes a áreas rurais, definidas pela Fundação Instituto Brasileiro de Geografia e Estatística - IBGE - ou aquelas situadas em área urbana, desde que atendam predominantemente a populações do campo. O PNLD Campo tem como objetivo distribuir materiais exclusivos para professores e alunos do campo, visando atender as principais demandas desse contexto específico, qual sejam: classes multisseriadas, apenas um docente para todas as disciplinas, poucos alunos em cada classe, distância da zona urbana, entre outros.

Este trabalho visa contribuir com a discussão sobre a análise de políticas públicas tendo o PNLD Campo como foco. Assim, este artigo tem três principais objetivos: (1) acercar-se do Programa Nacional do Livro Didático Campo (PNLD Campo), com vistas a observar as especificidades do mesmo; (2) verificar as diretrizes relacionadas a letramento e língua portuguesa, de forma a desvelar diretrizes da política linguística subjacente aos documentos; e (3) investigar os critérios utilizados pelos professores de uma escola do campo para escolher o livro na primeira edição do Programa.

\section{PNLD Campo}

Questões relativas à educação no campo têm avançado principalmente nos últimos 13 anos. Programas educacionais foram criados para atender esses sujeitos sociais, firmando a inserção das discussões sobre o tema nas agendas das políticas públicas e de pesquisa de instituições. O PNLD campo, por exemplo, é apenas um programa dentre outras iniciativas que existem e que se propõem a contribuir para esse contexto em plano educacional. 
Algumas dessas iniciativas são: (1) Escola Ativa. Este programa concede bolsas de estudo e de pesquisa para educadores de instituições públicas de ensino superior, supervisores das secretarias estaduais de educação e a professores. (2) Projovem Campo: programa do governo federal destinado a agricultores com idade entre 18 e 29 anos, alfabetizados, mas que não tenham concluído o ensino fundamental. (3) Procampo: o Programa de Apoio à Formação Superior em Licenciatura em Educação no Campo oferece graduação a professores das escolas rurais que lecionam nos anos finais do ensino fundamental e no ensino médio. (4) Construção de escolas: o Programa de Construção de Escolas no Campo, desenvolvido pelo governo federal, oferece a estados e municípios projetos arquitetônicos de escolas com tamanhos de uma a seis salas de aula.

Dessa forma, o PNLD Campo se edifica como uma política pública de reconhecimento da Educação do Campo e como um objeto que possibilita refletir o contexto do campo, os sujeitos que ali vivem, suas identidades, proporcionando, dessa maneira, a geração de propostas pedagógicas com temáticas e conteúdos condizentes com a matriz referencial. A (então) coordenadora-geral dos Programas do Livro Didático no FNDE Sonia Schwartz explica:

Os livros do PNLD Campo têm configuração diferenciada e podem ser multisseriados, multidisciplinados e divididos por áreas de ensino. Às vezes, na mesma sala, há alunos de idades diferentes, de séries diferentes, e esse novo modelo de livro pode atender melhor a realidade da escola rural. (SCHWARTZ, 2012) ${ }^{5}$.

Segundo informações do FNDE, o PNDL Campo atende escolas públicas rurais com até 100 alunos do $1^{\circ}$ ao $5^{\circ}$ ano do ensino fundamental e visa disponibilizar coleções que foram elaboradas com diferentes e específicas metodologias voltadas para a realidade do campo, com conteúdos curriculares que acolham os saberes das comunidades rurais, valorizando a identidade dos alunos que nela vivem e, principalmente,

5 Citação retirada do pronunciamento de Sonia Schwartz. Disponível em: http://portal.mec.gov.br/index. php?option $=$ com_content $\&$ view $=$ article $\&$ id $=17575$ :ensino-fundamental-de-escolas-rurais-tera-obrasdiferenciadas- $\&$ catid $=211$ 
evitando a estigmatização de estereótipos da comunidade do campo. O PNLD pretende considerar as especificidades do campo em relação também ao contexto político, ambiental, econômico, de raça e etnia, levando em conta uma concepção pedagógica própria da educação do campo e a necessidade da elaboração de materiais didáticos que atendam todas essas demandas.

Com essa iniciativa, o Ministério da Educação busca fomentar a produção de obras didáticas que superem o quadro atual das produções existentes caracterizadas para o ensino seriado, fragmentado, orientado pela lógica da oposição entre o urbano e o rural, muitas vezes, inadequadas à perspectiva didática e pedagógica, pois alheias às diretrizes operacionais formuladas para a educação básica das escolas do campo. (BRASIL, 2011, p. 27).

As coleções didáticas selecionadas do PNLD Campo seguem obrigatoriamente as diretrizes da Política de Educação do Campo, em cumprimento ao Decreto $n^{\circ} 7352$, de 4 de novembro de 2010, a Resolução CNE/CEB n ${ }^{0}$ 1/2002, a Resolução CNE/CEB n² 2/2008 e a Resolução $\mathrm{CNE} / \mathrm{CEB} \mathrm{n}^{\circ}$ 4/2010. Desenvolvida pela União, em colaboração com os estados, o Distrito Federal e os municípios, as diretrizes entendem que as políticas de educação do campo destinam-se a ampliar e a qualificar a educação básica e superior nesse contexto. Os públicos específicos do campo aos quais o PNLD Campo se destina são:

[...] os agricultores familiares, os extrativistas, os pescadores artesanais, os ribeirinhos, os assentados e acampados da reforma agrária, os trabalhadores assalariados rurais, os quilombolas, os caiçaras, os povos da floresta, os caboclos e outros que produzam suas condições materiais de existência a partir do trabalho no meio rural. (BRASIL, 2011, p. 29).

Os componentes curriculares abordados são: Alfabetização Matemática, Letramento e Alfabetização, Língua Portuguesa, Matemática, Ciências, História e Geografia, integrados em coleções multisseriadas ou seriadas ${ }^{6}$ destinadas a alunos matriculados em

6 As coleções multisseriadas são aquelas que reúnem um componente disciplinar em cada volume destinado ao $1^{\circ}, 2^{\circ}$ e $3^{\circ}$ anos e ao $4^{\circ}$ e $5^{\circ}$ anos. Ou seja, há apenas um volume do componente Letramento e Alfabetização, 
escolas do campo das redes públicas de ensino. As coleções didáticas são compostas por volumes de livros destinados aos segmentos A ( $1^{\circ}$ ao $3^{\circ}$ ano) e $B\left(4^{\circ}\right.$ ao $5^{\circ}$ ano), os quais são concebidos e organizados em coleções integradas, disciplinares7, por área de conhecimento, ou interdisciplinares. Os volumes únicos8 que constituem a coleção didática podem agrupar livros de diferentes disciplinas de uma série e de um segmento de aprendizagem ou apresentarem conteúdos de uma mesma disciplina para diferentes séries. $\mathrm{O}$ trabalho pedagógico é organizado por eixos temáticos, impedindo a compartimentalização de conteúdos rígidos, e pela transversalidade, organizando, dessa forma, temas que podem estar integrados a todas as disciplinas.

Obrigatoriamente, em todos os volumes, devem ser incluídos um manual do professor e, preferencialmente, DVD-Roms com textos, vídeos, imagens, entrevistas, músicas, mapas, jogos educativos, simuladores etc. Dessa forma, podemos ver que houve modificações quanto ao tipo de obras do primeiro para o segundo edital:

Geografia e História para os três primeiros anos do Fundamental, e um volume de Língua Portuguesa, Geografia e História para o $4^{\circ}$ e $5^{\circ}$ anos. As coleções seriadas são compostas por um volume de um componente disciplinar para cada ano do ensino fundamental. Por exemplo, um volume de arte para o primeiro ano, outro livro para o segundo ano etc.

7 Uma das características das coleções didáticas organizadas por disciplinas é a presença de volumes unifícados ou integrados. Chamamos aqui de volume único os livros que agrupam diferentes disciplinas de uma série ou de um segmento de aprendizagem num mesmo volume ou que apresentam os conteúdos de uma mesma disciplina para várias séries ou segmento de aprendizagem num único volume. Quanto à abordagem interdisciplinar, caracteriza-se por organizar o trabalho pedagógico por eixos temáticos, limitando a dispersão do conhecimento, propiciando a concretização da proposta pedagógica centrada na visão interdisciplinar, superando o isolamento das pessoas e a compartimentalização de conteúdos rígidos (BRASIL, 2011, p. 31).

8 Entende-se por volume único a obra didática individual organizada em torno de uma proposta pedagógica única, podendo atender turmas seriadas ou multisseriadas. 
Quadro 1 - Caracterização das coleções PNLD Campo 2013 e 2016

\begin{tabular}{|c|c|}
\hline 2013 & 2016 \\
\hline $\begin{array}{c}\text { I - Multisseriada Interdisciplinar Temá- } \\
\text { tica }\end{array}$ & $\begin{array}{c}\text { Composição Tipo I - Seriada Interdisci- } \\
\text { plinar }\end{array}$ \\
\hline II- Seriada Multidisciplinar Integrada & $\begin{array}{c}\text { Composição Tipo II - Multisseriada } \\
\text { Interdisciplinar }\end{array}$ \\
\hline III- Seriada Multidisciplinar por Área & $\begin{array}{c}\text { Composição Tipo III - Multisseriada } \\
\text { Interdisciplinar Temática }\end{array}$ \\
\hline $\begin{array}{c}\text { IV- Multiseriada Multidisciplinar por } \\
\text { Área }\end{array}$ & \begin{tabular}{c} 
Composição Tipo IV - Livro Regional \\
\hline
\end{tabular} \\
\hline
\end{tabular}

Provavelmente, a maior inovação no Edital de 2016 seja a inclusão do tipo Livro Regional, que deve apresentar apenas um volume e abordar conhecimentos de História, Geografia, Arte e Cultura de forma integrada. O livro deve registrar "a experiência de grupos que se identificam por fronteiras espaciais e socioculturais" (BRASIL, 2014, p. 63).

\section{Caracterização e avaliação das obras}

Um ciclo do PNLD envolve um processo longo de inscrição, avaliação, seleção e distribuição dos mesmos, que começa três anos antes de eles chegarem aos alunos. Um edital é publicado para que as editoras inscrevam seus livros seguindo as diretrizes exigidas por cada programa, nesse caso, o PNLD Campo. Após as inscrições, as coleções didáticas inscritas passam por três momentos avaliativos antes de serem aprovadas: triagem, pré-análise e avaliação pedagógica. A triagem se constitui em um exame para verificar aspectos físicos e atributos editoriais das coleções inscritas, em conformidade com os requisitos estipulados no edital. A pré-análise consiste em analisar se as obras contemplam o atendimento do objeto e da documentação definidos no edital. A avaliação pedagógica, realizada por instituições públicas de educação superior, verifica se as coleções estão de acordo com as orientações e diretrizes pedagógicas estabelecidas pelo Ministério da Educação a partir das especificações e dos critérios fixados no edital.

Após tais etapas, as coleções devem ser avaliadas e elegidas pelos 
professores das escolas cadastradas no PNLD Campo: os professores podem optar pelas coleções por meio do Guia do Livro Didático, doravante GLD, que explica as características de cada coleção através de resenhas das coleções aprovadas, os princípios e critérios que nortearam a avaliação pedagógica, os modelos das fichas de análise e as demais informações sobre o processo de escolha. Os professores são instruídos a realizarem uma reunião para discutir, avaliar e escolher o livro que será utilizado no triênio seguinte pela escola. Segundo o Edital do PNLD Campo 2013: “As coleções didáticas serão livremente escolhidas pelas escolas participantes, por meio de seu corpo docente e dirigentes, com base na análise das informações contidas no Guia de Livros Didáticos" (BRASIL, 2011, p. 13). Porém, como veremos a seguir, o GLD não é fundamental para a escolha do material didático. As editoras, por conta própria, enviam para as escolas exemplares das obras ${ }^{9}$, possibilitando que o professor possa manusear os livros antes de escolhê-los. Esta é considerada uma estratégia de marketing por parte das editoras, pois os professores acabam fazendo uma avaliação impressionista ${ }^{10}$ da obra com base no seu manuseio, e não nas informações e nas resenhas contidas no GLD redigidas pelos especialistas de cada área.

O PNLD Campo, para o período de 2013 a 2015, teve 18 obras inscritas, em atendimento ao edital de convocação. A distribuição por tipo de composição foi a seguinte: 4 coleções para o Tipo I (Multisseriada Interdisciplinar Temática); 4 coleções para o Tipo II (Seriada Multidisciplinar Integrada); 6 coleções para o Tipo III (Seriada Multidisciplinar por Área); 4 coleções para o Tipo IV (Multisseriada Multidisciplinar por Área). Do conjunto de 18 coleções avaliadas no PNLD Campo 2013, 16 (87\%) foram excluídas e 2 (13\%) foram aprovadas. As coleções aprovadas foram Coleção Girassol: Saberes e Fazeres do

9 Há, entretanto, normas explícitas sobre a interferência das escolas durante o período de escolha: "os representantes dos editores ficam impedidos de acessar as dependências das escolas e secretarias para realizar divulgação dos títulos participantes, e ficam proibidos de participar de eventos das escolas e secretarias destinados à realização das escolhas. Às escolas e secretarias não é permitido aceitar vantagens oferecidas pelos editores e seus representantes" (BRASIL, 2015b, p. 1).

10 Cunningsworth (1995) distingue dois tipos de avaliação de um LD, a avaliação impressionista" e a "avaliação profunda". A primeira consiste em formar rapidamente uma impressão sobre o LD, realizando uma observação rápida do livro, adquirindo uma visão global e geralmente superficial das suas possibilidades de uso. A avaliação profunda é mais detalhada na sua abordagem e segue a sua própria agenda, exigindo mais tempo. 
Campo e Coleção Projeto Buriti Multidisciplinar.

Para a edição de 2016 (2016 a 2018), cujo Guia foi publicado em 2015, foram inscritas 10 obras da seguinte forma: 1 coleção para o Tipo I (Multisseriada Interdisciplinar Temática); 3 coleções para o Tipo II (Seriada Multidisciplinar por Área); 6 livros regionais. Das 4 coleções avaliadas no PNLD Campo 2016, duas (50\%) foram excluídas, e duas (50\%) foram aprovadas, quais sejam, Coleção Campo Aberto e Coleção Novo Girassol: Saberes e Fazeres do Campo (também aprovada no edital passado). Entre os livros regionais, quatro (66.66\%) foram reprovados e duas (33,33\%) obras foram aprovadas: Tempo de Aprender: Região Norte e Cultura e Regiões do Brasil. Assim, apesar de o PNLD Campo 2016 ter tido menos obras inscritas, quando comparado à edição anterior, houve mais obras aprovadas, com a inclusão de dois livros regionais. Entretanto, ainda são poucas as obras consideradas satisfatórias a ponto de serem aprovadas nas avaliações, o que resulta numa menor cartela de opções para os professores desse segmento.

\section{Políticas Educacionais Linguísticas: a língua portuguesa como texto}

Este trabalho lança mão do arcabouço teórico-metodológico do Ciclo de Políticas, de Ball e colaboradores (BOWE; BALL; GOLD, 1992) para a análise de políticas educacionais. Os autores, primeiramente, entenderam o Ciclo como contendo três contextos: (1) contexto de influência; (2) contexto da produção do(s) texto(s) da política; (3) contexto da prática. Dois anos mais tarde, Ball (1994) acrescentou mais dois contextos ao Ciclo: o contexto dos resultados (efeitos) e o contexto da estratégia política (MAINARDES, 2006). Ao longo de seu trabalho, Ball rejeita fortemente a ideia de que as políticas sejam implementadas (MAINARDES; MARCONDES, 2009), pois isso preconizaria um processo linear (processo este também rejeitado por Ball) e altamente hierárquico, sugerindo que uma política se resumiria aos seus textos legislativos que requerem apenas a sua implementação de forma simples e uniforme. Para Ball (1994), o processo de traduzir políticas em práticas é extremamente complexo, demandando que o foco da análise de políticas deveria 
incidir sobre a "interpretação ativa que os profissionais que atuam no contexto da prática fazem para relacionar os textos da política à prática" (MAINARDES, 2006, p. 50). Nesse sentido, serão analisados alguns dos documentos do PNLD Campo (a saber, editais e Guias do Livro Didático) e, em seguida, investigação do contexto da Prática, mais especificamente, a interpretação e a ação dos atores sociais, nesse caso, os professores, com relação ao processo de escolha das coleções didáticas utilizadas no triênio 2013-2016.

Em adição aos pressupostos do Ciclo de Políticas, citamos Shohamy (2006), ao apresentar as Políticas Educacionais Linguísticas (PEL), mecanismos utilizados para criar práticas linguísticas principalmente em sistemas educacionais centralizados. Mais especificamente, as PEL referem-se a decisões relacionadas aos contextos educacionais com relação a línguas, quer sejam maternas ou adicionais. Essas decisões podem incluir questões tais como: as línguas a serem ensinadas na escola, a idade ideal para começar, por quantos anos, quantas horas de estudos semanais, quem está habilitado a ensinar, quais os métodos e materiais indicados, quais são os encaminhamentos dados para cada componente etc. Dessa forma, o PNLD Campo na área de Língua Portuguesa pode ser considerado uma PEL, na medida que os LDs do Programa orientam o trabalho na área de estudos da linguagem. Importante ressaltar que não há uma obrigatoriedade de que todos os conteúdos do livro sejam estudados, e nem que os conteúdos devam ser estudados na ordem em que estão no LD, pois o PNLD Campo compreende-se como "um contexto gerador de conteúdos, textos, temas, atividades, propostas pedagógicas, ilustrações e organização curricular do livro didático" (BRASIL, 2015 ${ }^{\text {, }}$ p. 8).

De forma a mapear as diretrizes do Programa para a Língua Portuguesa, apresentaremos informações sobre esse componente presente nos textos oficiais, a saber: Editais e GLDs das duas edições, 2013 e 2016. O Componente curricular Língua Portuguesa foi/é exigido nas seguintes composições em cada um dos dois editais:

\section{Quadro 2 - A Língua Portuguesa nas obras PNLD Campo}




\begin{tabular}{|c|c|}
\hline 2013 & 2013 \\
\hline $\begin{array}{l}\text { I-Multisseriada Interdisciplinar Temática } \\
\left.\text { SEGMENTO B ( } 4^{\circ} \text { e } 5^{\circ} \text { anos }\right) \\
\text { Tema 3: Língua Portuguesa, Matemática, } \\
\text { Geografia, História e Ciências }\end{array}$ & $\begin{array}{l}\text { Composição Tipo I - Seriada Interdisci- } \\
\text { plinar SEGMENTO B }\left(4^{\circ} \text { e } 5^{\circ} \text { anos }\right)\end{array}$ \\
\hline $\begin{array}{l}\text { I-Multisseriada Interdisciplinar Temática } \\
\text { SEGMENTO B }\left(4^{\circ} \text { e } 5^{\circ} \text { anos) }\right. \\
\text { Tema 4: Língua Portuguesa, Matemática, } \\
\text { Geografia, História e Ciências }\end{array}$ & $\begin{array}{l}\text { Composição Tipo II - Multisseriada } \\
\text { Interdisciplinar } \\
\left.\text { SEGMENTO B ( } 4^{\circ} \text { e } 5^{\circ} \text { anos }\right)\end{array}$ \\
\hline $\begin{array}{l}\text { II- Seriada Multidisciplinar Integrada } \\
\text { SEGMENTO B }\left(4^{\circ} \text { e } 5^{\circ} \text { anos }\right) \\
\text { Língua Portuguesa, Matemática, Geogra- } \\
\text { fia, História e Ciências } \\
4^{\circ} \text { ano }\end{array}$ & $\begin{array}{l}\text { Composição Tipo III - Multisseriada } \\
\text { Interdisciplinar Temática } \\
\left.\text { SEGMENTO B ( } 4^{\circ} \text { e } 5^{\circ} \text { anos }\right) \\
\text { Língua Portuguesa, Matemática, Geogra- } \\
\text { fia, História e Ciências -TEMA } 3\end{array}$ \\
\hline $\begin{array}{l}\text { II- Seriada Multidisciplinar Integrada } \\
\text { SEGMENTO B }\left(4^{\circ} \text { e } 5^{\circ} \text { anos }\right) \\
\text { Língua Portuguesa, Matemática, Geogra- } \\
\text { fia, História e Ciências } \\
5^{\circ} \text { ano }\end{array}$ & $\begin{array}{l}\text { Composição Tipo III - Multisseriada } \\
\text { Interdisciplinar Temática } \\
\left.\text { SEGMENTO B ( } 4^{\circ} \text { e } 5^{\circ} \text { anos }\right) \\
\text { Língua Portuguesa, Matemática, Geogra- } \\
\text { fia, História e Ciências -TEMA } 3\end{array}$ \\
\hline $\begin{array}{l}\text { III- Seriada Multidisciplinar por Área } \\
\text { SEGMENTO B }\left(4^{\circ} \text { e } 5^{\circ} \text { anos }\right) \\
\text { Língua Portuguesa, Geografia e História } \\
4^{\circ} \text { ano }\end{array}$ & \\
\hline $\begin{array}{l}\text { III- Seriada Multidisciplinar por Área } \\
\text { SEGMENTO B }\left(4^{\circ} \text { e } 5^{\circ} \text { anos }\right) \\
\text { Língua Portuguesa, Geografia e História } \\
5^{\circ} \text { ano }\end{array}$ & \\
\hline $\begin{array}{l}\text { IV- Multiseriada Multidisciplinar por } \\
\text { Área SEGMENTO B }\left(4^{\circ} \text { e } 5^{\circ} \text { anos }\right) \\
\text { Língua Portuguesa, Geografia e História } \\
4^{\circ} \text { e } 5^{\circ}\end{array}$ & \\
\hline
\end{tabular}

Fontes: Brasil (2011); Brasil (2014)

Conforme o Quadro 2, o componente Língua Portuguesa é exigido a partir do $4^{\mathrm{o}}$ ano ${ }^{11}$ em vários tipos de composição. Entretanto, como mencionado anteriormente, apenas duas coleções foram aprovadas no

11 Importante destacar que, antes do $4^{\circ}$ ano, o trabalho com a LP é chamado de letramento e alfabetização. Os princípios e objetivos do ensino da língua materna permanecem essencialmente os mesmos nos anos posteriores, sendo baseados no estudo do texto e nos contextos sociais inseridos nas diferentes linguagens. Analisamos, contudo, apenas os livros de $4^{\circ}$ ano em diante, como critério de recorte e de seleção da pesquisa. 
Edital de 2016, além dos livros regionais que, apesar de não trazerem a Língua Portuguesa como componente obrigatório no título dos livros, abrangem o trabalho com a língua e com a linguagem de diferentes maneiras.

Para ilustrar alguns dos critérios utilizados para a escolha e a consequente aprovação/reprovação da obra, reproduzimos algumas das perguntas encontradas na Terceira Parte da Ficha de Avaliação contida no GLD-Campo 2013 (BRASIL, 2012) e no GLD-Campo 2016 (BRASIL, 2015).

\section{Quadro 3 - Critérios de avaliação dos conteúdos curriculares no PNLD Campo 2013 e 2016.}

\section{Análise avaliativa dos conteúdos curriculares e da proposta de ensino e aprendizagem \\ GLD Campo 2013 (BRASIL, 2012, p. 46-47)}

A coletânea textual favorece experiências diversificadas de leitura e constitui-se como um instrumento de acesso do aluno à cultura escrita?

A coleção apresenta fontes de natureza variada e referências materiais e imateriais da cultura, incluindo aquelas produzidas na experiência social do campo, indicando possibilidades de abordagem e de interpretação para a produção de conhecimento?

A coleção recorre a diferentes formas de linguagem (gráficos, mapas, tabelas, fotos e gravuras) adequadas às situações de ensino-aprendizagem?

A coleção promove diálogos com outras linguagens (cinema, rádio, televisão etc.)? A coleção estimula a utilização de recursos didáticos diversificados: materiais

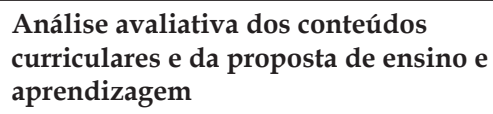

O Livro Regional favorece experiências diversificadas de leitura e constitui-se como um instrumento de acesso do aluno à cultura escrita?

O Livro Regional apresenta referências materiais e imateriais da cultura do lugar e regional, incluindo aquelas produzidas na experiência social do campo, indicando possibilidades de abordagem e de interpretação para a produção de conhecimento?

O Livro Regional recorre a diferentes formas de linguagem (gráficos, mapas, tabelas, fotos e gravuras) para expressar fatos e fenômenos históricos, geográficos, artísticos e culturais?

O Livro Regional promove diálogos com outras linguagens (cinema, rádio, televisão etc.)? 
concretos, jogos, calculadora, outros recursos tecnológicos, leituras complementares?

As atividades colaboram para a formação de leitores, sendo variadas e explorando múltiplas dimensões do universo textual?
As atividades colaboram para a formação de leitores, sendo variadas e explorando múltiplas dimensões do universo textual?

O livro trabalha de forma a favorecer que a criança desenvolva autonomia para compreender o mundo que a cerca e para interpretar as situações do dia a dia?

As atividades colaboram para a formação do leitor literário?

As atividades situam a prática de escrita em contextos sociais de uso, propondo atividades variadas e explorando múltiplas dimensões do universo textual?

As atividades situam a oralidade em contextos sociais de uso, propondo atividades variadas e explorando as suas múltiplas dimensões?

A coleção propõe atividades adequadas para a alfabetização, favorecendo a aquisição do sistema de escrita da Língua Portuguesa? 


\section{Quadro 4 - Conteúdos curriculares listados para o trabalho de Língua Portuguesa nos guias PNLD Campo 2012 e 2015}

\begin{tabular}{|c|c|}
\hline $\begin{array}{l}\text { Habilidades listadas para o trabalho } \\
\text { de alfabetização/letramento e Língua } \\
\text { Portuguesa (BRASIL, 2012, p. 49) }\end{array}$ & $\begin{array}{l}\text { Habilidades listadas para o trabalho } \\
\text { de alfabetização/Letramento e Língua } \\
\text { Portuguesa (BRASIL, 2015a, p. 68). }\end{array}$ \\
\hline $\begin{array}{l}\text { Contribuir para o desenvolvimento de } \\
\text { capacidades de uso da língua. }\end{array}$ & $\begin{array}{l}\text { Contribuir para o desenvolvimento de } \\
\text { capacidades de uso da língua. }\end{array}$ \\
\hline $\begin{array}{l}\text { Utilizar diferentes estratégias de leitura; } \\
\text { construir a textualidade de acordo com o } \\
\text { contexto de produção e o gênero. }\end{array}$ & $\begin{array}{l}\text { Utilizar diferentes estratégias de leitura; } \\
\text { construir a textualidade de acordo com o } \\
\text { contexto de produção e o gênero. }\end{array}$ \\
\hline $\begin{array}{l}\text { Analisar as relações entre as modalidades } \\
\text { oral e escrita da língua em diferentes } \\
\text { práticas sociais e em diferentes gêneros. }\end{array}$ & $\begin{array}{l}\text { Analisar as relações entre as modalidades } \\
\text { oral e escrita da língua em diferentes } \\
\text { práticas sociais e em diferentes gêneros. }\end{array}$ \\
\hline $\begin{array}{l}\text { Avaliar o registro de linguagem adequa- } \\
\text { do à situação comunicativa. }\end{array}$ & $\begin{array}{l}\text { Avaliar o registro de linguagem adequa- } \\
\text { do à situação comunicativa. }\end{array}$ \\
\hline $\begin{array}{l}\text { A escolha de conteúdos e de conceitos é } \\
\text { adequada para alunos dos anos iniciais } \\
\text { do Ensino Fundamental? (BRASIL, 2012, } \\
\text { p. 50). }\end{array}$ & $\begin{array}{l}\text { A escolha de conteúdos e de conceitos é } \\
\text { adequada para alunos dos anos iniciais } \\
\text { do Ensino Fundamental? (BRASIL, } \\
\text { 2015a, p. 69). }\end{array}$ \\
\hline $\begin{array}{l}\text { Letras do alfabeto, tipos de letras, organi- } \\
\text { zação silábica, segmentação de palavras } \\
\text { e frases, ortografia, leitura e escrita de } \\
\text { palavras, frases, textos. }\end{array}$ & $\begin{array}{l}\text { Letras do alfabeto, tipos de letras, organi- } \\
\text { zação silábica, segmentação de palavras } \\
\text { e frases, ortografia, leitura e escrita de } \\
\text { palavras, frases, textos. }\end{array}$ \\
\hline $\begin{array}{l}\text { As atividades propostas ao longo da } \\
\text { obra estimulam o uso de estratégias de } \\
\text { raciocínio requisitadas para as diferen- } \\
\text { tes áreas do conhecimento? (BRASIL, } \\
\text { 2012, p. } 51 \text { ). }\end{array}$ & $\begin{array}{l}\text { As atividades propostas ao longo da } \\
\text { obra estimulam o uso de estratégias de } \\
\text { raciocínio requisitadas para as diferen- } \\
\text { tes áreas do conhecimento? (BRASIL, } \\
2015 \mathrm{a}, \text { p. } 70 \text { ). }\end{array}$ \\
\hline $\begin{array}{l}\text { Reflexão sobre os usos linguísticos na } \\
\text { diversidade de situações comunicativas, } \\
\text { quer sejam orais ou escritas }\end{array}$ & $\begin{array}{l}\text { Reflexão sobre os usos linguísticos na } \\
\text { diversidade de situações comunicativas, } \\
\text { quer sejam orais ou escritas. }\end{array}$ \\
\hline $\begin{array}{l}\text { Na coleção, há equilíbrio e articulação } \\
\text { entre os conteúdos trabalhados no } \\
\text { interior de cada área de conhecimento? } \\
\text { (BRASIL, 2012, p. 52). }\end{array}$ & $\begin{array}{l}\text { Na coleção, há equilíbrio e articulação } \\
\text { entre os conteúdos trabalhados no } \\
\text { interior de cada área de conhecimento? } \\
\text { (BRASIL, 2015a, p. 71). }\end{array}$ \\
\hline $\begin{array}{l}\text { Equilíbrio e articulação entre os eixos de } \\
\text { leitura, produção de textos, oralidade e } \\
\text { conhecimentos linguísticos (gramática). }\end{array}$ & $\begin{array}{l}\text { Equilíbrio e articulação entre os eixos de } \\
\text { leitura, produção de textos, oralidade e } \\
\text { conhecimentos linguísticos (gramática). }\end{array}$ \\
\hline
\end{tabular}

A leitura das fichas de avaliação permite afirmar que o ensino 
e a aprendizagem de língua materna no PNLD Campo devem ser orientados pela escrita e pelos discursos que se organizam a partir dela (BRITTO, 1997, p. 12): ler, pesquisar, interpretar, analisar, responder ao texto, produzir, apresentar e estudar as diferentes circulações do material escrito constituem-se como pontos de orientação. Estes pontos permitem inferir que a visão de linguagem adotada pelo PNLD situa-se numa perspectiva de letramento. Dessa forma, os textos selecionados para comporem as unidades didáticas devem pertencer a gêneros discursivos que representem a heterogeneidade do mundo escrito. Essa heterogeneidade não fica apenas restrita aos gêneros discursivos, mas diz respeito também às variedades linguísticas existentes na LP (sociais e regionais), aos estilos e a outros registros do mundo escrito. O edital de 2014 salienta essa premissa: "caberá ao LDP valorizar e efetivamente trabalhar a variação e a heterogeneidade linguísticas, situando nesse contexto sociolinguístico o ensino das normas urbanas de prestígio" (BRASIL, 2012, p. 57).

Esse pressuposto oferece a possiblidade de os alunos aperfeiçoarem os recursos linguísticos, conhecerem outros contextos sociais e comunicativos, constituídos historicamente e em constante dinamização, podendo escolher ou não fazer parte deles. A aula de português na escola, dessa forma, tem por função trabalhar com os diferentes contextos comunicativos, dando ao aluno o acesso à cultura escrita e à possibilidade de circular em diferes esferas de atividades humanas, os gêneros do discurso (BAKTHIN, 2003), para interatuar em distintas esferas sociais. Enfim, parte-se do ponto de vista de que:

[...] o recado da aula de português é que o objeto de ensino é o trabalho sobre a linguagem e de que a aprendizagem se traduz por novas formas de participação no mundo social, que se abrem a partir da experiência com novas práticas de letramento e a partir de novas compreensões das práticas já conquistadas. (SIMÕES, 2012, p. 42).

Ao comparar os quadros, percebemos que a nova edição (PNLD 2016) complexifica alguns pontos relacionados ao trabalho com a língua, à formação do leitor literário e aos textos pertencentes à realidade regional 
(principalmente quando analisamos os tópicos relacionados ao Livro Regional). Nesse sentido, percebe-se preocupação em se valorizar as produções culturais regionais, investindo no trabalho com produções de artistas locais. Além disso, o Guia da edição de 2016 indica que as coleções devam trabalhar com vistas a contribuir para o desenvolvimento de capacidades de uso da língua, oferecendo abordagem com textos orais e escritos que abranjam múltiplas dimensões do universo textual e que ofereçam a utilização de diferentes estratégias de leitura. $\mathrm{O}$ trabalho com o texto deve ser visivelmente situado, contextualizado e complexificado em suas práticas sociais, atravessando a construção da textualidade de acordo com o contexto de produção e do gênero. Deve-se oferecer experiências diversificadas de leitura, sendo importantes esses momentos de contato com a cultura escrita.

Há também uma preocupação adicional, na última edição, com a formação do leitor literário e com o oferecimento de múltiplas fontes de produções que relacionem os diversos tipos de linguagem (cinema, rádio, televisão etc.) (BRASIL, 2014, p. 54). Assume-se, com relação a esse item, que a aprendizagem da linguagem das formas literárias tem potencial de desenvolver e de sustentar as competências interpretativas do estudante ao longo da sua escolarização e de propiciar um diálogo efetivo entre as tantas linguagens que existem e nas quais o aluno circula na sua comunidade (FILIPOUSKI; MARCHI; SIMÕES, 2009).

A oralidade também é tratada de maneira especial no Guia da edição atual, estabelecendo que o trabalho deve ser uma oportunidade de aprender a ouvir a própria voz e a voz do outro a partir da articulação com os eixos de leitura e produção de textos escritos (BRASIL, 2014, p. 57). Visa-se, dessa forma, o desenvolvimento linguístico e a construção de conhecimentos por meio da consolidação de estudos na modalidade oral, com o cuidado de se garantir o equilíbrio e articulação entre os eixos de leitura, produção de textos, oralidade e conhecimentos linguísticos.

Percebe-se que, em relação ao quadro 4, as orientações mais gerais das habilidades e da adequação da proposta do LD para as séries iniciais do ensino fundamental não apresentam nenhuma modificação. As habilidades continuam baseadas na apresentação e no estudo de 
situações diversificadas de comunicação, por meio do texto oral ou escrito, subsidiando a participação em práticas letradas dos alunos e possibilitando momentos de estudos e de sistematização sobre a língua materna (recursos linguísticos). As perguntas presentes no Guia em relação ao trabalho com o texto direcionam para o desenvolvimento da proficiência em escrita. Propõe-se, junto a isso, que se realize um trabalho conjunto de aquisição do sistema alfabético, já que se trata dos primeiros anos do ensino fundamental: questões como ortografia, alfabeto, tipos de letras, organização silábica também são tidos como eixos essenciais.

Repetidas vezes, a adequação a determinadas situações de comunicação é reiterada como um importante item na hora de avaliar os LDs. A adequação comunicativa faz com que se consolide a premissa de que todos os textos têm interlocutores e propósitos específicos, são escritos por alguém, em um determinado lugar social, para um leitor que procura o texto com determinados objetivos. Percebemos que a visão de língua que deve permear o trabalho com a linguagem nos LD Campo gira em torno da Língua Portuguesa e de sua função social, ou seja, da reflexão de que o fazer humano repousa na linguagem. Tendo ciência de que "a unidade em torno da qual se faz todo o trabalho de Língua Portuguesa e Literatura é o texto, ponto de partida e de chegada, em torno do qual todas as tarefas propostas aos alunos se estruturam" (FILIPOUSKI; MARCHI; SIMÕES, 2009, p. 52).

Sendo assim, podemos afirmar que o trabalho com a língua materna oferecido aos estudantes por meio do LD Campo deve, para ser bem avaliado, possibilitar a experenciação da leitura de diferentes textos escritos que, por meio de atividades e tarefas de interpretação e de interação com os materiais escritos, abra espaço para os diferentes modos de ler e de circular pela cultura escrita (BRASIL, 2014).

\section{PNLD Campo: entre o contexto da produção do texto e da prática}

Para investigar um dos contextos da prática, foram utilizados 
questionários $^{12}$ respondidos por 13 professores de um município do interior do estado do Rio Grande do Sul que estão participando do Programa do governo federal Pacto Nacional para a Alfabetização. O curso foi dividido em módulos e aconteceu em encontros que deram conta do conteúdo de cada módulo. Os questionários foram compostos de perguntas baseadas nos documentos apresentados na seção anterior deste artigo. Os professores que responderam esses questionários assinaram o Termo de Consentimento Livre e Esclarecido, autorizando o uso das respostas.

A primeira questão se refere à própria formação dos professores. Existe grande diversidade no que concerne à formação dos professores do campo, sendo que a maioria deles, 31\% (4 professores), cursou a faculdade de Pedagogia na modalidade presencial; 31\% (4 professores) cursaram, além da graduação, uma pós-graduação ligada à área de atuação atual; 23\% (3 professores) cursaram magistério, formação ainda aceita no município até o último concurso público. Essa diversidade pode representar variadas posições em relação à concepção de ensino e do que se constitui como um bom material didático, nesse caso, o que se constitui como um bom LD.

Com relação ao tempo de trabalho, 77\% (10 professores) estão há mais de quatro anos na escola. Alguns detalharam: 33 anos, 20 anos, mais de 10 anos. Dois professores (15\%) responderam que lecionam há 4 anos, e um professor (8\%), há menos de um ano. A maioria dos professores leciona na mesma escola há mais de dois anos, sendo assim, 92\% dos professores estavam nas escolas nas quais ainda atuam quando da escolha das coleções do PNLD Campo 2013.

Sobre o LD ter sido tópico de discussão em algum momento dos cursos de formação, 69\% (9 professores) responderam que sim; enquanto $31 \%$ (4 professores) alegaram que o LD foi um tópico muito pouco tratado nos respectivos cursos de formação. Podemos inferir que o LD não é um assunto completamente desconhecido por nenhum dos professores, já que ninguém optou pela resposta possível não. Dessa forma, os docentes desta pesquisa têm alguma experiência teórica prévia em relação ao livro.

12 As perguntas que constituem o questionário foram baseadas em Silva (2014). 
Além disso, ao serem perguntados se já haviam utilizado o LD do PNLD do ensino fundamental, ou seja, o PNLD não específico ao campo, 100\% dos professores responderam positivamente. A mesma porcentagem está utilizando atualmente o LD do PNLD Campo em suas salas de aula. Esse dado é importante, na medida em que revela um posicionamento informado com base nas experiências anteriores com livros didáticos.

Com relação ao recebimento das coleções, 69\% (9 professores) dos professores receberam a coleção Girassol: Saberes e fazeres do campo. Além desses, 31\% (4 professores) marcaram que receberam as duas coleções aprovadas: Girassol: Saberes e fazeres do campo e Coleção Projeto Buriiti multidisciplinar. Como estava ${ }^{13}$ presente na reunião na qual foi realizada a geração dos dados, perguntei se as escolas receberam as duas coleções para serem utilizadas por todos os alunos. Porém, os professores responderam que receberam exemplares da Coleção Buriti para os docentes, e que, para os alunos, foi recebida a coleção Girassol: Saberes e fazeres do campo. O Programa prevê que cada escola receba apenas uma coleção, aquela escolhida pelos professores. Podemos inferir que o recebimento das duas coleções aprovadas pode ter sido uma atitude adotada pelo FNDE para que os professores tivessem materiais de apoio para complementar suas aulas.

Quando perguntados se todos os alunos receberam os LDs, apenas um dos professores respondeu que não, mas que não se lembrava de quantos estavam faltando, e que a escola não fez o pedido de remanejamento. A falta de LDs para todos os alunos da escola é fato recorrente de todos os Programas do Livro Didático do país. Baseado no censo escolar referente a dois anos anteriores, o FNDE faz o cálculo das obras segundo os dados dos alunos inseridos no site do Inep. De acordo com Sarmento e Silva (2012), o número de obras enviadas dificilmente coincide com o número de alunos matriculados, pois o montante não considera o registro de entrada e saída de alunos em anos seguintes ao do Censo, sendo, assim, necessário o remanejamento daquelas escolas onde estejam excedendo para aquelas em que ocorra falta de livros. Há também uma reserva técnica, que é um percentual de livros disponibilizado às Secretarias

13 Esta parte do texto é escrita em primeira pessoa porque apenas uma das autoras participou da reunião. 
Estaduais de Educação para atender novas turmas e matrículas. Porém, o acesso ao sistema de remanejamento parece não ser uma prática comum entre as escolas públicas. Assim como o professor desta pesquisa não solicitou os livros faltantes, as pesquisas de mesma natureza, Sarmento e Silva (2012; 2013) e Tagliani (2009), não registraram como uma ação recorrente o pedido de remanejamento. Segundo Sarmento e Silva (2012), tal fato pode acarretar problemas na sala de aula: os livros didáticos de língua estrangeira, assim como os do Campo, são consumíveis ${ }^{14}$, porém, com a falta de livros, muitos alunos precisam compartilhá-lo com outros colegas, não podendo, por exemplo, realizar as atividades no próprio livro.

Os livros do PNLD Campo são consumíveis, ou seja, os alunos não precisam devolvê-los ao fim do ano letivo e podem utilizá-los para a realização das tarefas propostas pelo próprio livro. Conforme o gráfico, $77 \%$ (10 professores) dos professores sabem que os alunos não precisam devolver os livros ao final do ano, $8 \%$ (1 professor) não respondeu e 15\% (2 professores) não sabiam. É importante observar que a maioria dos professores sabe que o LD é consumível, ponto muito importante do programa e que oferece ao aluno uma maior interação com o material distribuído pelo FNDE. A importância de os professores saberem que o LD pode ser, além de manuseado, escrito e rasurado pelo aluno, pode fazer grande diferença na qualidade do processo de ensino e aprendizagem. Na pesquisa realizada por Sarmento e Silva (2012) sobre a implementação do PNLD de Língua Estrangeira, a maioria dos professores desconhecia que o livro era consumível, prejudicando, dessa forma, a interação efetiva entre aluno, professor e livro.

É essencial dizer, no entanto, que o docente não pode ser culpabilizado pelo desconhecimento dessa informação. Como as autoras explicam, há vários possíveis fatores: um deles é a confusão gerada por uma carta enviada juntamente com todos os LDs das outras disciplinas que não são consumíveis. Enviada pelo FNDE, a carta alerta para a necessidade de conservação do LD para que, no ano seguinte, possa ser usado por

14 "Entende-se por livros didáticos consumíveis aqueles entregues para utilização dos alunos e professores, que passam a ter sua guarda definitiva, sem necessidade de devolução ao final de cada período letivo" (BRASIL, 2011, p. 3). 
outros alunos. A informação de que os LDs de Espanhol e de Inglês não seguem essa regra não é explicitada em lugar algum, a não ser apenas pela palavra consumível, na quarta capa dos mesmos.

A maioria dos professores $69 \%$ (9 professores) considerou adequada a coleção específica para o campo. Por outro lado, 31\% (4 professores) alegaram que o livro é parcialmente adequado ao contexto de ensino do campo. Entendemos que a adequabilidade do LD Campo apenas poderá ser percebida com precisão com um trabalho etnográfico de acompanhamento e de observação do processo de ensino e de aprendizagem, além de avaliar as obras. Importante salientar que, ao viverem essa primeira experiência com o PNLD Campo, para o ano de 2016, os professores terão posicionamento crítico calcado no uso do LD Campo durante três anos. Nesse sentido, Silva (2014) traz dados interessantes, ao realizar entrevistas com professores que escolheram os LDs na segunda edição do PNLD de Língua Estrangeira. Ao serem perguntados se a experiência de ter usado o LD na primeira edição do programa havia influenciado na escolha das novas obras, todos os professores responderam positivamente. Alguns deles alegaram que escolheram com mais cuidado, pois os livros anteriores "eram muito ruins". Outros argumentaram que utilizaram critérios de comparação com os LDs da edição anterior, principalmente ao avaliarem atividades e a abordagem de conteúdos. Dessa forma, a escolha do próximo LD tem a possibilidade de ser mais cuidadosa à medida que acontece após o uso de um LD.

Além de utilizarem o Livro Didático, os professores informaram que fazem uso de outros materiais, sobretudo daqueles por eles mesmos produzidos. Uma participante desta pesquisa escreveu "O Livro Didático é só mais uma ferramenta, utilizo outros materiais". Sarmento e Silva (2013) confirmam que a maioria dos professores usa o LD, porém, seguem utilizando outros materiais de acordo com seu próprio planejamento. Conforme a mesma pesquisa, os professores usam o artefato de diferentes maneiras: selecionam unidades que consideram adequadas para suas turmas, escolhem atividades complementares às tarefas já elaboradas pelo professor, ou ainda o utilizam como guia de conteúdos. Essa 
pergunta não foi realizada especificamente aqui, como na pesquisa de Sarmento e Silva (2013), contudo, a relevância de conhecer o uso que os professores fazem do livro é grande, no que concerne à autonomia docente.

Ao serem perguntados sobre as principais diferenças entre o PNLD Campo e outras edições do PNLD, uma vez que todos já haviam utilizado outros formatos do LD e, atualmente, utilizam o LD Campo, os professores responderam:

- Que faz com que o aluno pense, acho que é um grande desafio.

- Ele influencia a maneira de pensar do aluno.

- De acordo com a realidade/manuseio e uso pelo aluno/ atividades interessantes.

- A adequação dos conteúdos às realidades do aluno.

- Ele está de acordo com a nossa realidade.

- O PNLD Campo trabalha mais com a realidade do nosso aluno da zona rural.

- Vem mais ao encontro da nossa realidade e necessidades. Enfatiza melhor os conteúdos com atividades lúdicas.

- Está de acordo com a nossa realidade.

Todas as respostas estão conectadas à proposta de abordar a realidade do campo e de trazer, para isso, atividades que concretizem essa interação. Apesar de 4 professores terem respondido que consideram o PNLD Campo apenas parcialmente adequado ao contexto de ensino, todos destacaram esse enquadramento como um diferencial positivo. Além disso, a maioria dos professores, em conversa, enquanto completavam o questionário, falou que o LD Campo possui proposta de articulação entre as diferentes áreas, e que as obras reconhecem o modo próprio de vida das populações do campo. Sendo assim, podese concluir que os professores destacaram a diferença entre as duas vertentes do Programa, salientando a adequabilidade do LD à realidade do campo. Contudo, ressaltamos que nem todos os LDs do Programa Nacional são avaliados de uma maneira tão positiva quanto parece que 
está sendo pelos professores das escolas do campo desta pesquisa. Silva (2014) transcreve relatos de professores de Língua Inglesa que teceram comentários negativos quanto à quantidade de atividades e conteúdos, à apresentação gráfica (poluído demais) e à inadequação de textos e tarefas.

A não participação dos professores na escolha do LD representa 85\% (11 professores); e apenas 15\% (2 professores) participaram. Os professores alegaram, em conversa paralela ao preenchimento do questionário, que os livros chegaram à escola sem eles estarem sabendo do processo de seleção, e nem que haveria uma mudança no PNLD. Esse dado é importante, na medida em que revela tanto a não participação dos professores na escolha das coleções quanto o não conhecimento da existência desse momento de escolha e avaliação. As causas do desconhecimento podem ser várias e devem ser investigadas detidamente em futura entrevista que será realizada com os mesmos professores. Contudo, pode-se aventar a hipótese de haver falha de comunicação entre a Secretaria de Educação do município com os professores das escolas, pois, segundo eles, que representam $85 \%$ do efetivo, nenhum convite foi feito para que eles participassem do processo.

Conforme os dois professores que participaram da escolha do LD, ela aconteceu em uma reunião com os professores do município e foi feita por meio de discussão e análise das coleções enviadas como material de divulgação pelas editoras, e não com o GLD, como previsto no próprio Guia. Esses dois professores fazem parte da coordenação pedagógica da Secretaria de Educação e trabalham na Prefeitura. Dessa forma, essa poderia ser uma explicação para que apenas esses dois professores soubessem do acontecimento do processo de escolha. Contudo, somente pelo questionário, não conseguimos saber quais eram os outros professores do município que participaram da referida reunião e nem quando ela aconteceu precisamente.

Ao serem perguntados sobre se utilizaram o GLD, nenhum dos professores respondeu à questão. Tal fato pode significar o desconhecimento dos passos do programa e até mesmo de regras contidas no edital, elaboradas para o correto funcionamento da política pública. Nesse ponto, as contribuições de Sarmento e Silva (2012) e Silva 
(2014) apontam para a repetição em outros contextos do não uso do GLD para a escolha dos livros, como também do desconhecimento da escolha dos LDs. Na pesquisa supracitada, de um universo de 19 participantes docentes, 8 não haviam participado da escolha e 5 não sabiam como a escolha havia acontecido. Dos que participaram, nenhum deles utilizou o GLD como auxílio para a escolha das coleções. Silva (2014) conclui que os docentes acabam por realizar uma seleção impressionista (CUNNINGSWORTH, 1992) por meio dos materiais de divulgação enviados pelas editoras. Esse fato pode ser explicado pela falta de tempo para se fazer uma avaliação criteriosa (avaliação profunda) e até mesmo pelo desconhecimento da existência de recursos disponíveis para a escolha, como o próprio GLD. Tagliani (2009), ao realizar sua pesquisa em 4 escolas de uma cidade do sul do Brasil em relação à escolha do LD de Língua Portuguesa do triênio 2008-2011, destaca também que o GLD não é utilizado como base para o processo avaliativo dos livros. É como se o Guia não tivesse nem chegado a essas escolas. Ela avalia de forma negativa essa constatação, já que o Guia é o produto final de todo um processo de avaliação e trabalho de leitura e análise atenta de especialistas nas diferentes áreas. O Guia poderia ajudar sobremaneira na escolha de materiais com qualidade diferenciada e elevada, como também orientar a percepção de se as obras dão mais ênfase a um ou a outro aspecto, se as obras estão adequadas às necessidades atuais do aluno e se estão inseridas em diferentes contextos.

\section{Considerações finais}

O PNLD destinado ao Campo se constitui como grande avanço e reconhecimento das populações rurais, já que a realidade nessas zonas exige a adequabilidade do ensino e, consequentemente, do LD que auxilia intensamente os professores em suas salas de aula. Os critérios para a avaliação e para a seleção dos LDs Campo seguem o que aponta Britto (1997), pois consideram o texto como ponto-chave do processo de ensino e de aprendizagem nas aulas de Língua Portuguesa. Abordam a heterogeneidade dos gêneros do discurso e do mundo escrito sem 
deixar de valorizar as produções da região onde os alunos vivem. $\mathrm{O}$ foco dos LDs é oferecer espaços de experenciação em diferentes esferas da atividade humana nas quais textos orais e escritos são essenciais para a sua realização. Percebemos que a visão do ensino de Língua Portuguesa presente nos editais tem como premissa oferecer ao estudante a circulação em novas e diferentes práticas de letramentos (SIMÕES, 2012). É essencial destacar a importância de o professor conhecer a consistência dos critérios exigidos pelos editais. Esse conhecimento detalhado, quando da escolha das coleções, permite uma análise informada de um LD que poderá ter papel importante no trabalho de Língua Portuguesa na sua sala de aula nos três próximos anos.

Com relação às entrevistas, pode-se observar que os professores que utilizaram o PNLD Campo nesse último ano o consideraram adequado para o contexto de ensino, destacando a diversidade de propostas didáticas e a interdisciplinaridade. Contudo, percebeu-se a não participação dos docentes na escolha da coleção que passaria a ser seu objeto de trabalho. Dessa forma, torna-se necessária a disseminação da informação e do convite à participação dos docentes nesse processo, já que o programa recebe grandes investimentos e precisa, necessariamente, ser tratado com seriedade para que o contexto da produção do texto da política pública e o contexto da prática sejam coerentes e efetivos.

Além disso, é importante destacar a necessidade de pesquisas que, além de analisar os pressupostos e as orientações instauradas pelas PELs, investiguem e acompanhem os efeitos que as decisões tomadas na elaboração dos LDs Campo, por exemplo, causam no contexto educacional, conforme sugestão de Ball (MAINARDES; MARCONDES, 2009). Analisamos que a visão de ensino de língua e o trabalho com a linguagem são direcionados para o letramento. O próximo passo é saber se o LD realmente possibilita que essa visão de ensino se concretize na prática das salas de aula, verificando, dessa forma, como as políticas produzidas por instâncias públicas fazem diferença no contexto para o qual foram elaboradas. 


\section{Referências}

BAKHTIN, Mikhail. Estética da Criação Verbal. São Paulo: Martins Fontes, 2003 [1953].

BALL, Stephen J. Education Reform: A critical and post-structural approach. Buckingham: Open University Press, 1994.

BOWE, Richard; BALL, Stephen J.; GOLD, Anne. Reforming Education \& Changing Schools: Case studies in policy sociology. London: Routledge, 1992.

BRASIL. Edital de convocação para o processo de inscrição e avaliação de obras didáticas para o programa nacional do livro didático do campo PNLD Campo 2013. Brasília: MEC, 2011. Disponível em: < http://www.fnde. gov.br/programas/livro-didatico/livro-didatico-editais>. Acesso em: 14 jul. 2014.

BRASIL. Guia PNLD CAMPO 2013. Brasília: MEC, 2012. Disponível em: $<$ ttp://pronacampo.mec.gov.br/images/pdf/bib_guia_pnld_campo\%202013. pdf $>$. Acesso em: 14 jul. 2014.

BRASIL. Fundo Nacional de Desenvolvimento da Educação. PNLD: apresentação. Brasília, DF, 2012. Disponível em: <http://www.fnde.gov.br/ programas/livro-didatico/livro-didatico-apresentacao>. Acesso em: 14 jul. 2015.

BRASIL. Guia PNLD CAMPO 2016. Brasília: MEC, 2015a. Disponível em: $<$ http://www.fnde.gov.br/programas/livro-didatico/guias-do-pnld/item/6575guia-pnld-campo-2016-\%E2\%80\%93-anos-iniciais-do-ensino-fundamental>. Acesso em: 26 out. 2015.

BRASIL. Orientações para o Registro da Escolha do PNLD Campo 2016 (Anos Iniciais do Ensino Fundamental). Brasília, DF, 2015b.

BRITTO, Luis Percival Leme. A sombra do caos - ensino de língua x tradição gramatical. Campinas, Mercado de Letras, ALB, 1997. 
CUNNINGSWORTH, Alan. Choosing your coursebook. Londres: Heinemann, 1995.

FILIPOUSKI, Ana.; MARCHI, Diana.; SIMÕES, Luciene. Referencial Curricular de Língua Portuguesa e Literatura. In: RIO GRANDE DO SUL. Referenciais Curriculares do Estado do Rio Grande do Sul: Linguagens, Códigos e suas Tecnologias. Porto Alegre: SEqDP, 2009. p. 53-119. v. 1.

MAINARDES, Jefferson. Abordagem do Ciclo de Políticas: Uma contribuição para a análise de políticas educacionais. Educação e Sociedade, Campinas, v. 27, n. 94, p. 47-69, 2006. Disponível em: <http://www.scielo.br/pdf/es/v27n94/ a03v27n94.pdf $>$. Acesso em: 19 abr. 2014.

MAINARDES, J.; MARCONDES, M. I. Entrevista com Stephen J. Ball: um diálogo sobre justiça social, pesquisa e política educacional. Educação \& Sociedade, Campinas, v. 30, n. 106, jan./abr. 2009. Disponível em: <http://www. scielo.br/pdf/es/v30n106/v30n106a15.pdf $>$. Acesso em: 8 nov. 2015.

MOLINA, Mônica Castagna. Educação do Campo e Pesquisa: questões para reflexão. Brasília: Ministério do Desenvolvimento Agrário, 2006.

SARMENTO, Simone; SILVA, Larissa Goulart. A reconfiguração do Programa Nacional do Livro Didático pelos Atores Sociais. In: CONGRESSO BRASILEIRO DE LINGUÍSTICA APLICADA, 10., Rio de Janeiro, 2013. Anais Eletrônicos... Rio de Janeiro: ALAB, 2013. Disponível em <http:/ / www.alab.org.br/images/stories/alab/CBLA/ ANAIS2013/sarmento-e-silva.pdf>. Acesso em: 4 jul. 2014.

SARMENTO, Simone; SILVA, Larissa Goulart. The Book is (not) on the table: O Programa Nacional do Livro Didático no Cotidiano Escolar da Educação Linguística. In: CONGRESSO BRASILEIRO DE LINGUÍSTICA APLICADA, 9., Rio de Janeiro, 2012. Anais Eletrônicos... Rio de Janeiro: ALAB, 2012. Disponível em: <http:/ /www.alab.org.br/images/stories/ alab/CBLA/ANAIS/temas/24_12.pdf>. Acesso em: 8 ago. 2014.

SILVA, Larissa Goulart, A seleção do livro didático de língua estrangeira 
do programa nacional do livro didático. Porto Alegre: UFRGS, 2014.

SOARES, Magda. Letramento e escolarização. In: RIBEIRO, V. M. (Org.). Letramento no Brasil: reflexões a partir do INAF 2001. 2. ed. São Paulo: Ação Educativa; Global; Instituto Paulo Montenegro, 2003. p. 89-113.

SCHWARTZ, Sonia. Alunos de escolas rurais receberão livros didáticos diferenciado. Brasília, DF: Rede de Comunicadores, 2014. Disponível em: <http:/ / redecomunicadores.mec.gov.br/entrevistas-66021/781-alunosde-escolas-rurais-receberao-livros-didaticos-diferenciado $>$. Acesso em: 14 jul. 2014.

SIMÕES, Luciene Juliano. Leitura e autoria: língua portuguesa e literatura. Erechim: Edelbra, 2012.

TAGLIANI, Dulce Cassol. O Processo de Escolha do Livro Didático de Língua Portuguesa. Linguagem em (Dis)curso, Palhoça, v. 9, n. 2, p. 303-320, mai./ago. 2009. Disponível em: <http://linguagem.unisul. br/paginas/ensino/pos/linguagem/0902/090204.pdf>. Acesso em: 03 fev. 2014. 